\title{
Credibility Engineering in the Food Industry: Linking Science, Regulation, and Marketing in a Corporate Context
}

Citation for published version (APA):

Penders, B., \& Nelis, A. P. (2011). Credibility Engineering in the Food Industry: Linking Science, Regulation, and Marketing in a Corporate Context. Science in Context, 29(4), 487-515. https://doi.org/10.1017/S0269889711000202

Document status and date:

Published: 01/12/2011

DOI:

10.1017/S0269889711000202

Document Version:

Publisher's PDF, also known as Version of record

\section{Document license:}

Taverne

Please check the document version of this publication:

- A submitted manuscript is the version of the article upon submission and before peer-review. There can be important differences between the submitted version and the official published version of record.

People interested in the research are advised to contact the author for the final version of the publication, or visit the DOI to the publisher's website.

- The final author version and the galley proof are versions of the publication after peer review.

- The final published version features the final layout of the paper including the volume, issue and page numbers.

Link to publication

\footnotetext{
General rights rights.

- You may freely distribute the URL identifying the publication in the public portal. please follow below link for the End User Agreement:

www.umlib.nl/taverne-license

Take down policy

If you believe that this document breaches copyright please contact us at:

repository@maastrichtuniversity.nl

providing details and we will investigate your claim.
}

Copyright and moral rights for the publications made accessible in the public portal are retained by the authors and/or other copyright owners and it is a condition of accessing publications that users recognise and abide by the legal requirements associated with these

- Users may download and print one copy of any publication from the public portal for the purpose of private study or research.

- You may not further distribute the material or use it for any profit-making activity or commercial gain

If the publication is distributed under the terms of Article $25 \mathrm{fa}$ of the Dutch Copyright Act, indicated by the "Taverne" license above, 


\section{Credibility Engineering in the Food Industry: Linking Science, Regulation, and Marketing in a Corporate Context}

\section{Bart Penders}

Radboud University Nijmegen, The Netherlands ${ }^{1}$

Annemiek P. Nelis

University of York $^{2}$

\section{Argument}

We expand upon the notion of the "credibility cycle" through a study of credibility engineering by the food industry. Research and development (R\&D) as well as marketing contribute to the credibility of the food company Unilever and its claims. Innovation encompasses the development, marketing, and sales of products. These are directed towards three distinct audiences: scientific peers, regulators, and consumers. R\&D uses scientific articles to create credit for itself amongst peers and regulators. These articles are used to support health claims on products. However, R\&D, regulation, and marketing are not separate realms. A single strategy of credibility engineering connects health claims to a specific public through linking that public to a health issue and a food product.

\section{Introduction}

Scientific claims seem to have pervaded every corner of the world we live in. They are used to support political argument, promote products of various types, and discipline behavior. An important reason why scientific claims are used so abundantly is because they are believed to be more "true" or "valuable" than other claims. Their value lies in their credibility. It is, however, not always clear where that credibility comes from, how it has emerged, or how it is maintained. This becomes even more striking when the source of a scientific claim is not a knowledge producer we have grown accustomed to, e.g. a university, a research institute, or a public research organization, but rather

\footnotetext{
${ }^{1}$ Bart Penders is at the Centre for Society and Genomics and Department of Philosophy and Science Studies; Institute for Science, Innovation and Society (ISIS), Faculty of Science, Radboud University Nijmegen and the Department of Health, Ethics \& Society (HES), School of Primary Care and Public Health (CAPHRI), Maastricht University.

${ }^{2}$ Annemiek P. Nelis is an Affiliated Research Fellow at the Science and Technology Studies Unit (SATSU), University of York.
} 
a corporate laboratory. How and why does a for-profit knowledge producer produce credible claims? In this paper, we describe some of the inner workings of the R\&D process of one corporate laboratory of the multinational company Unilever. We aim to describe how, in corporate scientific practices, credibility is engineered among nutrition scientists and among consumers and how both those processes are intertwined.

Credibility engineering influences the research agenda of corporate and academic science alike, mostly, because it is thought to influence food and other consumption choices made by consumers. Independent scholars from areas such as nutrition science, food policy and health law, have all argued, on the basis of empirical research, that this influence is morally questionable (e.g. Lang and Haesman 2004; Nestle 2002; Simon 2006). Such critical inquiries into the normative and political consequences of credibility engineering and the ensuing consequences for public health are worthwhile because they display how corporate research influences our lives in unseen ways. The insights into credibility engineering presented in this paper will fuel future analyses in this area.

One of the themes of our research project is how the "credibility economy" of food products is established and maintained by the food industry. We are interested in this perspective for two reasons. First, we want to explore how food industry deals with the "public credibility market" and how both scientific knowledge and - for lack of a better term - "lay knowledge" intersect in this context. How does the food industry manage innovation in a scientific world known for its diverse and heterogeneous character and a consumer population that is, allegedly, looking for a healthy diet and responsible food? Secondly, we wanted to ask ourselves what science and technology studies (STS) could learn about industrial R\&D. Studies within STS have focused almost exclusively on knowledge production in public laboratories. Little attention has been paid to the knowledge production that exists beyond the academic laboratory: for-profit science or corporate science. Such corporate laboratories remain understudied (Penders et al. 2009; Shapin 2008).

In the past two years, starting early 2008, we have studied Unilever R\&D as a site of corporate science. Unilever is a large multinational company producing and selling consumer goods in more than 150 countries. Its annual turnover is almost 40 billion euros and its 2009 profit was approximately 3.6 billion. It employs more than 175,000 people, 6000 of whom are researchers in 6 research centers, and the R\&D headquarters is based in Vlaardingen, the Netherlands. The annual research budget is close to one billion euros (Unilever 2009b). In order to be able to study the internal dynamics of such a big organization, we have selected a number of cases drawn from the Unilever R\&D laboratories and offices at Vlaardingen and elsewhere in Europe, focusing in particular on Unilever as a food company (and in this article even narrower, as a margarine producer). ${ }^{3}$ One of these cases, margarine, is the topic of this paper.

\footnotetext{
${ }^{3}$ Cases were selected in dialogue with Unilever R\&D management. They include "healthy margarines," the topic of this paper, "ice structuring protein" and "metabolomics," two cases that are currently being studied and will be reported in future publications.
} 
While we acknowledge that its business activities range much further, the Dutch roots of the multinational can be traced back to margarine, a product which provided us with an interesting case-study.

Unilever has allowed us access to the relevant personnel, laboratories, offices, and archives. We have conducted in-depth interviews with Unilever researchers, research managers, and project managers (eleven in total), ${ }^{4}$ observed meetings, and visited laboratories and offices. We have watched and discussed television commercials, marketing, and communication strategies and innovation portfolios. ${ }^{5}$ To ensure that a critical distance to the object of study could be maintained, only one of the authors, Bart Penders, collected empirical material, while the other author, Annemiek P. Nelis, remained outside the food industry. The empirical material was subsequently analyzed by Bart Penders and discussed and evaluated by both authors and regularly presented to audiences both familiar and unfamiliar with corporate knowledge production. Ultimately, from this diverse set of empirical material, we developed the analysis presented here.

We will start by revisiting the study of credibility and the credibility cycle as it was proposed by Latour and Woolgar in 1979. Subsequently, we will describe the process of credibility engineering that we have observed in Unilever's R\&D and marketing sections and determine whether the 1979 credibility cycle also fits for-profit knowledge production. As we advance through our empirical description of Unilever's credibility engineering with respect to margarine and phytosterols, we will adjust the credibility cycle when required. We will conclude with an updated credibility cycle, suitable for studying for-profit knowledge production and credibility engineering.

\section{Studying credibility}

In 1975, Randall Collins pictured science as "an open plain with men scattered throughout it, shouting: 'Listen to me! Listen to me! ... The fundamental process is a competition for attention" (Collins 1975, 480). In scientific practices, shouting harder does not always get you more attention. Getting noticed requires an attribute that makes one stand out from the crowd, so to speak. In science, the chosen attribute is credibility or reputation. Reputation "highlights one's presence in the ... world" (van Lente and Rip 1998).

\footnotetext{
${ }^{4}$ Interviews were conducted in Dutch and English, determined by the native tongue of the interviewee (which, in the cases of Unilever R\&D is in no way correlated to the Dutch or British research laboratories or offices). All interview fragments from Dutch interviews have been translated by Bart Penders. Fragments drawn from interviews and presented here are exemplary of the types of arguments used or types of statements uttered by the interviewees.

${ }^{5}$ While Unilever previously cooperated with scholarly inquiry into its history (e.g. Fieldhouse 1978; Jones 2005; Wilson [1954/1968] 1970; Wubs 2008), studying its present has been a novel experience to Unilever too.
} 
In the often quoted article, "Cordelia's Love," Shapin describes how, starting in the mid-seventies with people like Randall Collins, STS scholars have studied the "credibility economy" alongside the study of (scientific) knowledge. Scientific knowledge requires more than being heard or talking the truth, rather it requires being accepted by others as credible source of knowledge. "In sociological terms of art, an individual's belief (or an individual's claim) was contrasted to collectively held knowledge. The individual's belief did not become collective - and so a part of knowledge - until and unless it had won credibility. No credibility no knowledge" (Shapin 1995, 257). ${ }^{6}$

Credibility is neither self-evident nor a permanent attribute of scientific claims. As science studies scholars have repeatedly demonstrated, it requires maintenance and active support to construct, gain, and uphold credibility. Existing studies of credibility have shown this work in different contexts, focusing for example on forensic science in the courtroom (Bal 2005; Lynch 2002), contested infrastructural projects (Perry et al. 2007), the emergence of ecology as a scientific discipline (Kinchy and Kleinman 2003), or the development of human growth hormone (Latour and Woolgar [1979] 1986). What these studies have in common is that they show credibility engineering as a continuous process.

Shapin (1995) lists three characteristics of the study of credibility. The first of these states that scientific claims are effective not because they resemble the truth but rather because they have gained credibility: scientific claims are no different from claims in ordinary life. The second states that there is no limit to the considerations that might be relevant to accruing credibility. As a result, there is no limit to what could be taken into consideration to understand credibility. The third states that there is not one single theory of how credibility is achieved. Rather this may differ in each case and can and will be rather diverse.

Let us briefly turn to Unilever to consider these points. First of all, as we will see throughout this paper, credibility is clearly an issue for Unilever. Within the company we encountered people talking about "credibility" all the time. Credibility was, for example, related to scientific claims as well as to marketing and corporate identity. In the words of a senior R\&D product leader: "As a part of society, when we communicate we are influencing our credibility. Others judge that credibility. To have and to keep credibility is the hardest job of all" (Observation V2, 20081209). The second of Shapin's characteristics states that anything can be relevant for obtaining scientific credibility. This is not limited to a particular setting or repertoire. Unilever deals with competing claims about evidence and effects concerning nutrition, food, and health on a daily basis. As we will show, credibility for the acclaimed effect of products is obtained through a variety of means: peer-review accreditation by international food agencies, advertising, key-opinion leaders, and endorsement by celebrities. The third

\footnotetext{
${ }^{6}$ One of the classical papers in the sociology of science argues that past recognition and allocation of credibility produce accumulative advantage, such that they accrue at ever higher rates, particularly compared to those judged less so in the past. Merton identifies this as "The Matthew Effect in Science" (Merton 1968).
} 
guideline implies that empirical study will reveal how credibility engineering works in practice. Rather than the employment of a particular theory, to understand the credibility economy of Unilever's products and markets, we had to study margarine and the claims that surround it in detail. As mentioned above, STS studied knowledge production mostly within public settings. Our study of Unilever R\&D reveals the production of credible claims in a commercial setting. While at first sight this may appear to resemble well-studied public research practices, upon close examination they turn out to be significantly different. Claims, we will show, emerge at the intersection of science, marketing, and (the building of) a corporate image. ${ }^{7}$

\section{Revisiting credibility}

One of the first studies that touched upon "credibility' as a resource for the production of scientific knowledge, has been Laboratory Life of Latour and Woolgar (1979). In this book, Latour and Woolgar show what scientists do to make their claims become uncontested "truths" and how they enable further research by strengthening their reputation and - on the basis of this reputation - funding. The cyclical process that Latour and Woolgar describe includes the conversion or, in their words, translation, from proposals to money to data to results to recognition and back to proposals again. This is the "credit cycle" of science.

Latour and Woolgar first coined "the cycle of credit" in 1979. Given the central role of recognition and prestige in the credit cycle, it has also been named the "credibility cycle" (van Lente and van Til 2008; Packer and Webster 1996). According to Latour and Woolgar, time, money, and effort are translated into data. Sets of data are used to construct a line of argumentation, which is subsequently written down in publications. Scientific peers will either notice or read the publication, or even cite it, which will result in (additional) recognition for the claim in that publication that cites it. The newfound or heightened recognition transferred to the author can be mobilized to support new funding requests. The new funding, supplemented with time and effort, will eventually result in new data. Every step in this cycle contributes to the credibility of the knowledge claims produced, the researchers involved and/or the group or laboratory in which the work has been done. If maintained successfully, this cycle will uphold the credibility of each of these. The cycle of Latour and Woolgar has been

\footnotetext{
${ }^{7}$ While there have been few studies of knowledge production in commercial settings, at least one example is worth mentioning here. This is Sismondo's study of pharmaceutical knowledge production (Sismondo 2007, 2009a, 2010). Sismondo describes how pharmaceutical companies today organize medical research and in particular clinical trials through so-called consultant research organizations (CROs). These organizations form an invisible workforce of research planners that nonetheless work hard to maintain both their own and their companies' credibility. In line with Sismondo, whose work we revisit in the conclusions to this paper, we will argue that corporate science and marketing are both important sources for building credibility and that rather than treating them as different parts of credibility engineering, they are in fact intimately intertwined.
} 


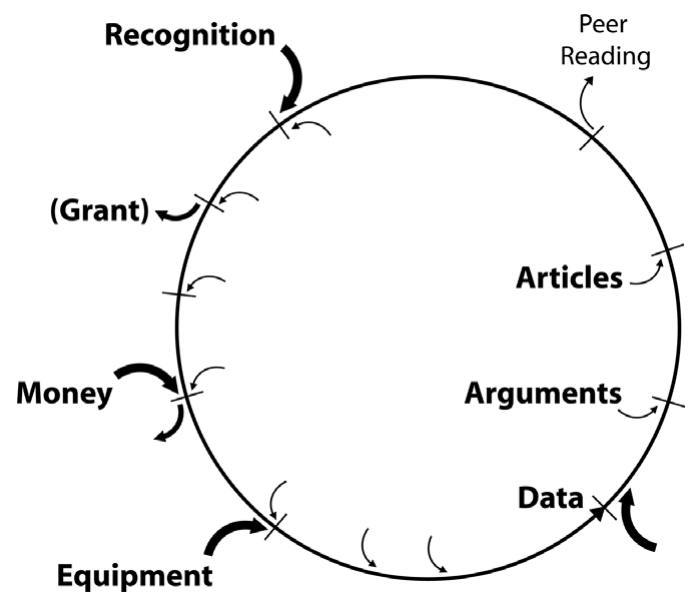

Fig. 1. The "cycle of credit" or "credibility cycle" by Latour and Woolgar. Redrawn, based upon Latour and Woolgar [1979] 1986.

summed up in a famous drawing (fig. 1). This cycle is described by Latour and Woolgar in terms of capital investments. Central to this capital investment are accepted scientific conventions such as academic publications and the process of peer-review.

Inspired by the work of Latour and Woolgar, several scholars have shown slightly different cycles of credibility engineering, such as the credibility-process that comes with patenting practices (Packer and Webster 1996): research councils and their agendas (Rip 1994), the pursuit of societal relevance (Hessels et al. 2009), and funding agencies and their portfolios (Nowotny et al. 2001). In some of these studies additional elements have been added to the original credibility cycle. Packer and Webster (1996), for example, have studied patenting cultures of university scientists in the UK. Based upon surveys, interviews and observations, they demonstrate that next to the cycle of credit centered around academic-peer-reviewed publications, a second cycle - centered on patents - may emerge. While credibility is constructed and maintained inside both these cycles, transferring credibility from one cycle to the other turned out to be less simple. To Packer and Webster this indicated that credibility engineering takes place in two distinct social worlds: academic peer-review and legal patents. The transfer from one to the other was only partly possible and required a lot of work.

Lehenkari has studied margarine innovation in Finland and the United States, also departing from Latour and Woolgar's credibility cycle. He describes how during the development of Benecol margarine, negotiations took place between actors outside and inside the innovation network. The producer of Benecol, the Finnish Raiso Margarine, occupied the passage point between outside and inside - thus being granted credit for the function and success of the product (Lehenkari 2000). He identifies three cycles, one taking place during product development, another during commercialization in 
Finland, and a third during commercialization in the United States. Lehenkari separates the cycles temporally from one another and reserves a grand role for scientific evidence, even in convincing consumers. He refers to mass media as a vehicle for careful and balanced reporting of this evidence, and shows the heterogeneous network Raiso Margarine built, in order to build credibility for this evidence with the general public (Lehenkari 2003).

While the patenting culture studied by Packer and Webster touches on private actors, their study was mostly limited to public laboratories. Lehenkari did study a network centering on a corporate actor, but does not explicitly aim to align the credibility cycle with corporate science. Here we will address if and how credibility engineering in corporate science differs from publicly funded science. Who are the audiences or targets of credibility in corporate science? Is achieving a credible status for a claim different in for-profit science? Departing from the credibility cycle as shown in figure 1 and discussed above, the sections below will sketch the context in which credibility engineering takes place in corporate science. We will start with some of the key-elements of Latour and Woolgar's credibility cycle, looking at the role of science, scientific articles, and peer-review in Unilever R\&D. In subsequent sections we will gradually move from scientific peers, via regulators to consumers and marketing and show how both science and marketing produce credible claims about food products.

\section{Credibility among peers}

Each year, Unilever scientists publish hundreds of articles in peer reviewed journals. ${ }^{8}$ This is not a small number and requires much effort. Articles do not publish themselves. Drawing from our own experience as academic authors, as well as from the literature on scientific work and publishing practices, we recognize that Unilever must commit significant resources to generate these publications. Throughout our observations and interviews, however, we are constantly reminded that the production of academic output is not the core task of Unilever R\&D. Nevertheless, Unilever is willing to conduct and pay for this work. One of the Unilever R\&D supervisors explained that "the goal of publishing is to maintain our prestige in the scientific world" (Interview V2, 20081006). This prestige is not sought after because of any intrinsic value, as one of the Unilever scientists explains, but serves several strategic goals:

We have a slightly different goal [compared to universities] when it comes to all sorts of external linkages, collaborations and publications. [To] us, publications can be purely

\footnotetext{
${ }^{8}$ A Scopus search of Unilever as an author affiliation revealed 330, 377, 372, and 301 articles published in 2009, 2008, 2007, and 2006 respectively. Overall, Scopus lists over 7800 articles in which Unilever is listed as the affiliation of one or more authors (checked February 4, 2010). While many of the articles represent public-private collaborations, others list Unilever as the affiliation of the sole, lead, or all authors.
} 
directed towards reputation, or they serve as evidence base for certain claims we make accompanying certain products. It requires referring to peer reviewed data. Additionally [publications help] in being credible towards certain external partners. (Interview V4, 20081215)

The scientist quoted here gives three goals for the production of scientific publications. First, publications aid in establishing one's reputation as a knowledge producer. Second, scientific publications provide support for product claims in the market place. And third, scientific publications increase the credibility of the company, something that is important if others judge the value of the work that Unilever does. With respect to the latter, another Unilever scientist explains:

[An] important reason to participate in the academic circus of publications is to enter certain circles of key opinion formers, people who have influence in or on the field nutrition and medicine. To be a credible partner to them, one needs to invest in, as well as deliver high quality work. Most of the partners we cooperate with are not dependent on the money we invest in such a collaboration. One has to be an interesting partner, asking interesting questions and performing good [science]. We try to show through peer-reviewed publication that we are able to. We show that we are an equal partner .... We try to publish high quality work, which gets us invited to conferences and to universities. That makes us a partner. (Interview V5, 20081215)

Next to the three motivations mentioned earlier, a fourth reason to publish in peer reviewed journals has to do with human resource management within Unilever:

One can wonder "what does it help us, to be a well-respected partner?" Well, we do want to attract the best people. [Annually,] we hire at least 30 to 40 scientists, in Vlaardingen alone .... We do want to select from the candidates with the highest quality. The people who want to work here ..., we have to be able to offer them interesting questions. Call it a "license to operate," that is a phrase we use once in a while ... . If we do not do it, everything comes [crashing] down and one cannot uphold one's status as a serious research-based company. (Interview V5, 20081215)

Actively pursuing peer reviewed publications is reported to grant Unilever access to external knowledge producers, either as potential employees, or as potential partners. Like others, Unilever depends on interaction with other knowledge producers to produce knowledge of its own. A Unilever scientist explains: "If we publish highquality work, this will lead to more prestige, which [will in turn lead to] more contact, more possibilities and more access to the global scientific world ... If we get access to five renowned scientists that is more expertise than we have ourselves" (Interview V2, 20081006). Thus, prestige amongst scientists is a requirement for Unilever's ability to access expertise, either through contacts or through recruitment. The supporters enrolled in a coalition, or collaboration, can also be a source of prestige (Smith et al. 
2005) and maintaining prestige is important to Unilever's ability to innovate, for it maintains Unilever's position among other knowledge producers. This maintenance is performed through academic output including scholarly articles, but also through lectures given at universities, awarding research prizes and public-private co-operations. The latter often consists of post-doctoral researchers or $\mathrm{PhD}$ students who work at Unilever R\&D Vlaardingen. In the Netherlands, regular scientific publishing is a requirement for obtaining a $\mathrm{PhD}$ degree and Unilever $\mathrm{R} \& \mathrm{D}$ enables and actively supports this publishing requirement.

Although it is reasonable to assume that, given the existence of formal evaluation mechanisms (e.g. peer review), both corporate science and academic science should be treated equally, this is not always the case. As some complain: "[I]t is unscientific, as well as unfair, to discard or discount a study based solely on which investigator or institution conducted or funded it" (Barrow and Conrad 2006). However, Unilever is well aware that industrial science does not occupy the same societal and political niche as academic science (Interview V2, 20081006 and Observation V1, 20080415). As we will show, it carefully orchestrates its reputation amongst its many peers, acting upon a conviction that credibility is important and thus attempting to construct itself as credible as possible (Perry et al. 2007).

Engineering credibility amongst academic peers starts by setting up collaborations, publishing peer reviewed articles and by "forming networks of key-opinion formers" (Observation V1, 20081110). Key opinion formers (KOF) can be prominent scientists or policy makers. They are identified by Unilever based upon their expected ability to influence public opinion. For as far as KOF are scientists, Unilever R\&D attempt to mobilize their expertise. This is done either by consulting them directly at conferences, meetings, or via telephone calls, by reading their scientific publications, or by paying close attention to their non-academic actions, which may include television appearances, columns they write or letters they publish in newspapers. As one of the Unilever scientists claims "Traditionally, Unilever has always wanted to stay really close to the key opinion formers" (Observation V7, 20081110). ${ }^{9}$ Key opinion formers co-determine "whether evidence is admissible or legitimate. They determine proof of product" (Observation V7, 20081110; emphasis in original). To make sure that products and claims released by Unilever are accepted amongst academic peers, Unilever scientists actively engage with and consult (scientific) key opinion formers.

Briefly summarizing the four motivations for peer-reviewed publishing, we can recognize (1) the construction of prestige, (2) support for product claims, (3) enabling network building, and (4) self portrayal as a science-minded employer. When we consider these motivations with respect to the credibility cycle of Latour and Woolgar, this part of the activities of Unilever very much resembles knowledge production in

\footnotetext{
${ }^{9}$ This scientist continues to argue that this will act as a hurdle to innovation because it favors conservatism.
} 
a public laboratory (from the perspective of a company): the construction of prestige or recognition, the desire to build networks with peer knowledge producers, and the need to strengthen credibility through subsequent projects. Unilever, however, also is different from the laboratory culture described by Latour and Woolgar. To Unilever, peers are important not only because they review scientific texts, they also judge claims in the context of regulatory practices.

\section{Regulatory gains}

Product claims range from statements of safety (safe to consume, apply to skin, etc.), to compliance, to regulations (safety regulations, content and packaging regulations, etc.), to health or functionality claims (e.g. "lowers your cholesterol") and much more. Such claims can also be found beyond the food industry, for instance accompanying cosmetics, cars, or lawnmowers. Often, such claims are checked and approved by regulatory bodies.

The evidence required to legally allow Unilever to use health claims on nutrition in the member states of the European Union, is judged by the European Food Safety Authority (EFSA), which assembles expert panels to issue a "scientific opinion" on these proposed health claims. The final decision lies with national organizations dealing with food safety and admissibility, in the Netherlands this is the Voedsel en Waren Autoriteit (VWA). The VWA or its sister organizations across Europe will receive the scientific opinion of the EFSA and let their decision be guided by it. The EFSA expert panels consist of academic scientists, some of which are key-opinion formers.

The EFSA Panel on Dietetic Products, Nutrition, and Allergies is an ad-hoc committee assembled to weigh evidence presented by companies who wish to accompany food products with health claims. In 2008 this Panel answered "Question No EFSA-Q-2008-085." This Question was presented by Unilever (EFSA 2008) through the publication of a "scientific opinion." Both question and opinion deal with the health effects of plant sterols. They address health claims connected to the sterols-in-product-context, not connected to specific product brands. This means that other food producers will also be able to use a similar claim for a similar product. The Unilever products that contain plant sterols and which are the most likely to be accompanied by this particular health claim, are the Flora/Becel proActiv brand categories of margarine.

Unilever scientists assembled evidence in a lengthy health-claim dossier. Part of this evidence is drawn from literature and part the result of (as yet) unpublished studies by Unilever itself. The whole collection is subsequently handed over to EFSA and the panel writes a scientific opinion weighing this evidence. Afterwards, the results appear in the EFSA Journal, and in this particular case, also appeared in many newspapers in the Netherlands and the rest of Europe. Alongside the evidence, Unilever proposed the following potential wording for their health claim: 
Plant sterols have been proven to lower/reduce blood cholesterol significantly. Blood cholesterol lowering has been proven to reduce the risk of (coronary) heart disease.

Plant sterols are proven to lower/reduce blood cholesterol significantly. Blood cholesterol lowering is proven to reduce the risk of (coronary) heart disease.

Product x contains (added) plant sterols proven to lower/reduce blood cholesterol. Blood cholesterol lowering reduces/has been proven/shown to reduce the risk of (coronary) heart disease (EFSA 2008, 6).

The EFSA panel ruled that none of these options were entirely correct and that a different framing "reflects the scientific evidence" better (ibid., 9):

Plant sterols have been shown to lower/reduce blood cholesterol. Blood cholesterol lowering may reduce the risk of (coronary) heart disease. (Ibid.)

If one compares the definitive wording as decided by the panel to the suggested wording by Unilever, the differences are small, yet substantial. How did this panel motivate this specific rewording and why are these differences so important?

In the case of Flora/Becel proActriv, the EFSA panel argues that studies "have indicated a causal relationship between elevated LDL-cholesterol and CHD" (EFSA 2008) and "there is evidence that the risk of CHD is reduced by cholesterol lowering therapy ..., including dietary intervention" (EFSA 2008). ${ }^{10}$ Nevertheless, the panel motivates the rewording of the health claim by the observation that "there are no human intervention studies demonstrating that plant sterols reduce the risk of coronary heart disease" (EFSA 2008, 8). While in pharmaceutical testing randomized clinical trials are considered the golden standard, in nutrition science usually "human intervention studies" fulfill this role:

Human intervention studies are the hardest because they are the least controllable. However. . . at the same time they are still, as my nutritionist-colleagues will confirm, the golden standard: double-blind, placebo-controlled. If you can show an effect that way, and you are able to repeat it, you end with the strongest possible backing for a claim. (Interview V4, 20081215)

\footnotetext{
10 This "scientific evidence" reflects a compromise reached by a number of peers, referring to evidence of blood cholesterol lowering in the general population. Evidence is presented in the form of claims such as "the daily intake of 2 to $2.4 \mathrm{~g} / \mathrm{d}$ of plant sterols or stanols added to margarine ... reduced on average low density lipoprotein (LDL) blood cholesterol levels by 8.9\% (95\% CI: 7.4-10.5)" (EFSA 2008, 8; Katan, Grundy, Jones, Law, Miettinen and Paoletti 2003). Rephrased, this tells us that 95 per cent of the people who consume between 2 and 2.4 grams of plant sterols through daily margarine consumption had their blood cholesterol lowered between 7.4 and 10.5 per cent. To the average European, this would result in a blood cholesterol level lowering of 8.9 per cent. It is this average European which is addressed in the proposed and accepted health claim and who is reflected in the evidence as judged by the panel.
} 
While evidence may exist and studies may have been conducted, the "proper scientific character" of the evidence is highest in the human intervention study. Claims thus have to be backed by "the gold standard" for the panel to legitimize the original wording. ${ }^{11}$ Due to the lack of a particular human intervention study, the claim will have to be 'toned down': blood cholesterol lowering may reduce CHD.

The panel's advice is relatively positive, especially considering that the wording was revised only slightly as compared to a large number of health claims which were checked simultaneously and were considered not attainable, given the provided evidence. In this case, Unilever has been relatively successful in establishing the credibility of its claim in this peer forum:

EFSA, the ways it works now, is forming a filter for [product or health] claims. Currently, a huge number of claims circulate and it is expected that more than three quarters will end up in the dustbin [due to EFSA regulations]. That our claims have been approved or have been awarded for the most part provides us with a competitive advantage. Simultaneously it acknowledges our science. EFSA has become a credibility filter. (Observation V1, 20090123; emphasis added)

Unilever acknowledges EFSA as an institution able to grant credibility to claims and pursues a positive scientific opinion from them. ${ }^{12}$ EFSA's positive judgment has, however, not resulted in complete consensus. Despite EFSA's judgment and the evidence provided by Unilever, in some scientific circles some disagreement regarding the claims connected to Flora/Becel proactive remains. ${ }^{13}$

Unilever's interaction with EFSA about the health claim connected to plant sterols and stanols deals with a single claim. Establishing the credibility of that one claim transfers a little credibility to the claimant, Unilever. Interestingly, just as with the credibility cycle described by Latour and Woolgar, it is in fact a small group of people "doing" the engineering and acquiring the credibility: authors on publications are identified first by their names and second by their affiliation. It is only though the continuous engineering of credible claims and the continuous exchange of credibility between claim and claimant that the credibility of Unilever itself can be strengthened (as

\footnotetext{
${ }^{11}$ In the context of nutrition science, a strict 5-step hierarchy of scientific evidence has been proposed by the ANZFA (now Food Standards Australia New Zealand) (see Truswell 2001 for a critical discussion).

12 The formalized regulatory status and role of EFSA, as well as the willingness of the European food industry to cooperate with it, suggests that nutrition science may follow medicine into a field in which objectivity, authority and credibility emerge from a regulatory framework that follows an internal ratio of evidence production (Cambrosio et al. 2006). The importance of EFSA in credibility engineering is also demonstrated when companies such as Winclove and Danone, retract all their dossiers before EFSA was able to support or deny them - to avoid any bad publicity, harmful to the credibility of the submitted claims.

${ }^{13}$ For instance, studies report disturbed metabolism caused by plant sterols (Gylling et al. 2009) or warn of impaired endothelial function and potential brain injury (Weingärtner et al. 2008).
} 


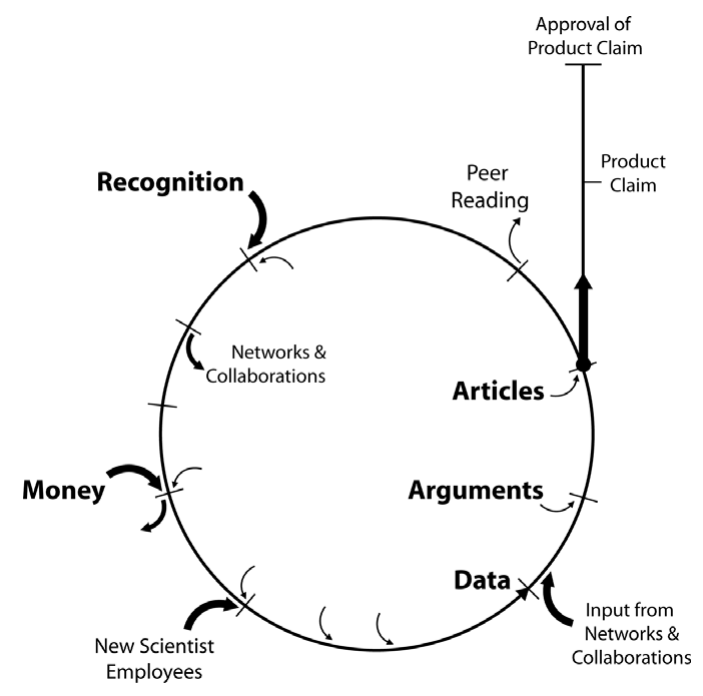

Fig. 2. The cycle of credibility of corporate science in academia. Despite a few different names and labels, the essence of credibility engineering is unaltered. The main expansion is the mobilization of articles and arguments for product claim support: a move into the regulatory domain.

mentioned in section 4). A single credible claim does not make the claimant credible this requires repetition and repeated transfer. The large amount of data produced and articles published (cf. note 8) as well increasing numbers of health claim dossiers submitted, continuously feeds Unilever's credibility cycle. In order to generate as few as possible hurdles for this credibility transfer, no subdivisions of Unilever R\&D are listed on publications. It is just "Unilever R\&D" or "Unilever Research Labs."

Figure 2 shows the cycle of credibility as it exists regarding Unilever R\&D. The labels are slightly different, but the essence of engineering credibility among academic peers remains unchanged. Certainly, Unilever's pursuit of credibility is also a cycle which sustains Unilever's ability to do R\&D. Prestige enables contacts and access to (new) knowledge, which enables certain innovation trajectories and knowledge output, which in turn sustains prestige or recognition. However, the mobilization of scientific knowledge in the realm of European food regulations warrants an expansion of the credibility cycle beyond immediate peers to include this second audience: regulators.

Regulators enhance the credibility of Unilever's claim that, for instance, phytosterols in margarine spreads may reduce blood cholesterol, by judging and approving of it. Subsequently, credibility is transferred to Unilever itself. Because of this it is of great importance to Unilever and the food industry generally that the regulators themselves are highly credible. Considering the central role regulators play in translating scientific 
credibility into consumer credibility, a highly credible EFSA (or equivalent in other countries) is in their best interest. ${ }^{14}$

Despite this expansion of the credibility cycle (shown in fig. 2), for a company like Unilever, this cycle is far from complete. If credibility were restricted to scientists, $\mathrm{R} \& \mathrm{D}$ professionals, and regulators, this would mean an omission of the essence of a corporation. The goal of Unilever is not to "do R\&D” or to generate knowledge. It is to sell products. To do so, credibility amongst consumers is what is really needed: "What ultimately matters most, is the credibility towards the consumer. That is plain and simple. He will have to buy it. Credibility towards scientists is a means to that end. Towards our customers, supermarkets, and the like, we need to have the same relationship" (Observation V2, 20081209).

\section{Credibility among consumers}

As a global food producer, Unilever produces, sells, and markets foods worldwide. An increasing number of these products is accompanied by claims. These can be, for instance, claims about the product's content (e.g. sugar free) or claims concerning its health effects (e.g. lowers cholesterol). As described above, under current regulations such claims require expert approval. Nevertheless, even when a health claim has been tested and approved, consumers may not always find these claims relevant. During one of our discussions, dealing with claims about cognitive and mental enhancement that would be induced by vitamins and mineral additives, one of the R\&D managers reports that "such claims are plausible to the people [in India and Indonesia] and they believe that a rich source of iron and other minerals may generate such effects. In Europe, this is different because consumers know that they are well fed, so why would this [small change] have such a large effect? It is about understanding what consumers consider credible." "15 Lack of credibility amongst consumers will quickly translate into loss of sales and profits.

One particular risk to the credibility of claims and companies is when claims are being contested. Diets for example, in a number of occasions, have been the topic of fierce disputes. Steven Shapin has compared the credibility of nutrition science and scientists with the credibility of authors of popular diet books and methods. As Shapin rightly observes, the prescriptions of nutrition scientists are often rejected or ignored

\footnotetext{
${ }^{14}$ As EFSA was initially set up, and more specifically when regulatory structures had to be designed with respect to dealing with health claims in Europe, EFSA approached, among others, the food industry to design such regulations (Observation V1, 20090123). Interestingly, the entanglement of the food industry's and EFSA's credibility need not necessarily be understood as a conflict of interest in this case, but may alternatively be perceived as a shared interest, as one of the Unilever research directors argues: "The credibility of EFSA's scientific committee needs to be guarded" (Observation V1, 20090123).

${ }^{15}$ Interestingly, the word "credible" was used in English in this interview conducted in Dutch. Interview V2, 20081006.
} 
while the prescriptions uttered by authors of diet books, including Atkins (with a diet named after himself), Agatston (the South Beach diet), Tarnower (the Scarsdale diet), Bakker (the Dutch, Sonja Bakkeren), are taken up with much enthusiasm: "[they are] the ones who are clearly winning in the marketplace of dietary credibility" (Shapin 2007, 180). The authors of do-it-yourself methods are more successful in engineering credibility for their dietary approach than nutrition scientists. Shapin suggests that they use a particular strategy for taming the contested nature of claims: a case-based approach.

While nutrition science is based on universal claims and knowledge that is or should be universally valid, best-selling books make use of the opposite: they describe the particular, making use of individual cases and stories. Dr. Atkinson for example, describes the story of Mrs Finkenstein, Stanley Moskowitz, and Mary Anne Evans, each being a particular age, living under particular circumstances and suffering from particular health problems. These three individuals allow for easy identification for the general public. Nutrition science, on the other hand, deals with populations, with the average men or women and with statistical figures that are epidemiologically sound and meaningful. Such figures do not translate easily into individual risks or gains. "The problem, however, is that people tend to be interested in what is likely to happen to them. The answer for any specific individual will either be colon cancer or no colon cancer, die before age 75 or after age $75 "$ (ibid., 184-185).

Unilever not only makes use of the scientific repertoire that lingers on universal claims (such as induced by the regulatory framework of ESFA) but also uses casebased approaches. Their main marketing strategy for example, is centered on a set of propositions concerning life and health, called the "life goal model." This model consists of 6 goals for life that have been formulated on the basis of market research (see table 1). The goals are expected to guide all activity within Unilever, including R\&D and marketing. Each of these life goals is connected to one or more of Unilever's particular brands and brand families. The goals are articulated by an expression in the first person ("I"). This first person perspective reveals personal focus, a case-study approach. Take for instance the life goal healthy for longer. It is connected to brands such as Bertolli and Flora/Becel and is expressed through the phrase: "If I'm going to live longer, I want to stay fit. My heart, my body and all my senses need to stay strong. If I take care of my body, my long-term health will take care of itself' (Banga 2006). Unlike, for instance, the EFSA scientific opinion, there is neither talk of the average European, nor the average consumer whatsoever. The key is in the "I". Together with Unilever, we have moved into the realm of marketing, and marketing is all about being personal.

Let's look closer at one of the marketing strategies as it is presented by Unilever. For symmetrical purposes we will be using the same product as above: Flora/Becel proActiv margarine. Communication with consumers is generally done via well-known marketing channels: advertisements on television, in magazines, and, increasingly, on the internet. Those attempting to change eating habits often do so by means of mass 
Table 1. Unilever has focused its actions around a number of key focal areas or brand categories (the Life Goal Model). These areas are repeatedly identified with particular brands, as listed. Connected to these focal areas, key expressions, fitting a logic of the particular, are used again and again. These can be found at many places, sites and documents in marketing practices or research. A readily available public source, is for instance Banga (2006).

\begin{tabular}{|c|c|c|}
\hline Life Goal & Brands & Key Phrase \\
\hline $\begin{array}{l}\text { Give Children a } \\
\text { Good Start }\end{array}$ & Flora/Becel, Planta & $\begin{array}{l}\text { I want my children to have the best possible } \\
\text { lives. And a big part of that is making sure } \\
\text { they eat good food, helping their bodies } \\
\text { and minds develop strongly. }\end{array}$ \\
\hline $\begin{array}{l}\text { Be Free from Health } \\
\text { Problems }\end{array}$ & Oral Care & $\begin{array}{l}\text { So many people have food-related problems - } \\
\text { allergies, intolerances, diabetes, irritable } \\
\text { bowel syndrome, the list goes on. I don't } \\
\text { want that - I want solutions today to lead a } \\
\text { happy, healthy life. }\end{array}$ \\
\hline Healthy for Longer & Bertolli, Flora/Becel & $\begin{array}{l}\text { If I'm going to live longer, I want to stay fit. } \\
\text { My heart, my body and all my senses need } \\
\text { to stay strong. If I take care of my body, my } \\
\text { long-term health will take care of itself. }\end{array}$ \\
\hline Look Better & Slim Fast & $\begin{array}{l}\text { If I look better, I feel better. So I'm searching } \\
\text { for things that will help me manage my } \\
\text { weight, keep me fit and active - and if they } \\
\text { make me look a bit younger, even better! }\end{array}$ \\
\hline Feel Good Daily & Ben \& Jerry’s, Dove & $\begin{array}{l}\text { I know I can affect my mood by making good } \\
\text { choices, including what I eat. I want things } \\
\text { that will relax my mind, help me sleep well } \\
\text { and generally make me feel good. }\end{array}$ \\
\hline Achieve More & $\begin{array}{l}\text { Lipton, Knorr, } \\
\text { AdeZ }\end{array}$ & $\begin{array}{l}\text { I want to do more, and there's more pressure } \\
\text { on me to do everything - at work and at } \\
\text { home. I need to boost my physical and } \\
\text { mental energy levels, and recharge my } \\
\text { batteries. }\end{array}$ \\
\hline
\end{tabular}

communication (Lien 1993). Here, we will draw from an example of two television commercials. $^{16}$

Advertisements can be read as technologies of persuasion as well as technologies of credibility. Like Dr. Atkins, who presents us with the case of the already mentioned Stanley Moskowitz, "a vigorous 64-year old sculptor who ... survived

\footnotetext{
${ }^{16}$ Both television commercials are part of a single narrative and tell two subsequent parts of a story. Both commercials can be found online for viewing purposes. See $<$ http://nl.youtube.com/watch?v=pRMDZvq8$\mathrm{NY}>$ for part 1, (last accessed March 2, 2010), and < http://nl.youtube.com/watch?v=bTMmHY49uR4> for part 2 (last accessed March 2, 2010).
} 
three heart attacks" (Atkins 1994, 16), Unilever presents us with Karin, a 48-year old singer/performer, overweight and living a hectic life, who learns that, as a result of menopause, her cholesterol level has increased. Karin is a Dutch celebrity. We are presented with at least two small stories in 30-second blocks. In the first story Karin, who believes that she is going through menopause in excellent health, is led to be unsure about her cholesterol levels. In the second story she has learned that her cholesterol needs to be lowered and has decided to do so by using Flora/Becel proActiv products. We are shown that she doesn't even need to change her lifestyle significantly to reach her goal of lowered cholesterol. On the Becel website, Karin explains it herself: "I didn't know anything about menopause ... . That I may have a higher risk of high cholesterol during menopause, I never heard about that, and neither did my friends."17

Unilever - via Karin Bloemen and the approved claim - links a social concern (high cholesterol) to a daily food-product (Flora/Becel). Instead of directly addressing a particular group or public, a public is formed rather through the connection of high-cholesterol with menopause and the desire to live longer and healthier (in the first commercial). This then is connected to phytosterols in margarine (in the second commercial). The life goals, in other words, are used by Unilever to create an issue, and with this issue, a public (Marres 2007). Issue and public are subsequently connected to the product while Karin Bloemen can be considered the vector to establish that connection.

A display of "cases" of well-known individuals, in commercials and throughout corporate communication and marketing, allows for a "metaphorical extension" (Shapin 2007) onto oneself. Karin Bloemen, the main character is well-known to the Dutch audience. Her approximate age is known and so are, for instance, details of her lifestyle, weight, and political affiliation. This particular marketing campaign is specifically directed at women in menopause: "As a result of the changes in your body during menopause, chances rise that you will have heightened cholesterol."18 The focus on first person and second person narratives is meant to facilitate this metaphorical extension. The "I" and "you" do not signify the average Dutchman or European. They represent women in menopause or who are concerned about entering menopause and who can identify with Karin Bloemen. However, not everybody can identify with this Dutch diva. For that reason, parallel cases are shown on TV: men and women in other age categories with different professions, accompanied by different narratives. These cases are positioned in such a way that, through metaphorical extension, they correspond to all (or most) members of the target audience.

\footnotetext{
${ }^{17}$ This text fragment was drawn from the Unilever website <http://www.becel.nl/Consumer/ Article.aspx?Path=Consumer/CholesterolAdvice/LoweringYourCholesterol/30dagenMinidrinkactie $>$ (last accessed November 26, 2008; translated by Bart Penders).

${ }^{18}$ This text fragment was drawn from the Unilever website <http://www.becel.nl/Consumer/ CampaignArticle.aspx?Path=Consumer/CholesterolAdvice/TippingPointCampaign/Home\&Campaign= true $>$ (last accessed November 25, 2008; translated by Bart Penders).
} 
Karin is certain about her need to act upon her cholesterol levels. She is not distracted by possible heterogeneous evidence about how to influence cholesterol levels, effects of diverse sorts of fatty acids, plant sterols and stanols, and much more. Her narrative is a homogeneous message along the lines of Unilever's life goal model: If I take care of my body, my long-term health will take care of itself. Such homogeneity, as Ronteltap (2008) explains, aids acceptance: "although not good for scientific progression, consensus ... is desirable from the perspective of consumer acceptance." Unilever is awarded credit for helping people like Karin to live a healthier life. The homogenous message and the possibility to metaphorically extend from Karin to many other women is rewarded with recognition. Unilever itself reports that " 80 per cent of Dutch women now know that there is a direct link between the menopause and cholesterol levels. At the start of the campaign this was less than 20 per cent" (Unilever 2009a). The "Brand Momentum" monitor of the Euro RSCG advertising agency reported the Karin Bloemen campaign to have generated the highest "consumer momentum" in the food category. ${ }^{19}$

Commercials promoting Flora/Becel proActiv do mobilize scientific evidence to show such products have an effect on cholesterol. The product package reports data about the amounts of calories, fatty acids, and phytostyroles. Many scientific claims surround Flora/Becel proActiv and Karin Bloemen in the public domain: these are the claims that have been approved by EFSA. Their regulatory approval (or scientific opinion) helps generate homogeneity in the marketplace and restricting heterogeneity to the scientific realm. In the margarine marketplace, science cannot engineer credibility all by itself. It can only help. Perry has demonstrated that activists in infrastructural debates, combine science with alternative credibility engineering strategies. If science doesn't suffice, or is unable to create an advantage, professionals seek out new trajectories: "at the same time, they exploit personal identities and embodied subjectivities as additional sources of authenticity and credibility" (Perry et al. 2007). Credibility engineering is a process that includes multiple publics. When these publics are consumers, science takes up a different, secondary role. Credibility engineering among consumers does not take the same cyclical shape as the credit cycle in academia (see figure 3, sales do not simply feed back into new approved health claims).

\footnotetext{
${ }^{19}$ Per season (summer 2008), as compared to other A brands. "Consumer momentum" or "Net Momentum" is defined as follows: "Respondents are confronted with a large amount of brands. [This] will lead to brand specific scores. The current strength of a brand, as perceived by the respondents, is expressed in the 'Net Momentum'. The higher the Net Momentum, the better the brand performance." The Brand Momentum is published regularly on <http://www.brandmomentum.nl/>, the particular measurement I refer to, describing Becel/Flora's "Net Momentum" can be found at <http://www.brandmomentum.nl/research_3_category_5.html> (last accessed April 6, 2009).
} 


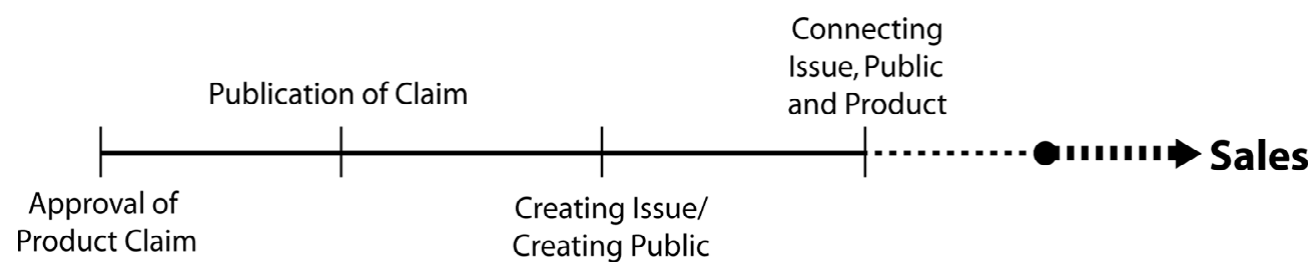

Fig. 3. Credibility engineering among consumers. This scheme shows a process usually identified as marketing. Approved health claims are mobilized, as well as particular individuals who are selected for their possibility to metaphorically extend across others. Prestige is engineered, but in radically different ways. The dotted line towards "sales" indicates that other factors, including but not restricted to the financial situation of the consumer or the availability of competing products with similar claims, co-determine whether sales will increase.

\section{Tying corporate science, regulation, and marketing together}

Thus far, we have described three related activities within Unilever: the production of credibility among scientific peers, the translation of this credibility into regulatory approval, and the production of credibility among potential consumers. We have shown that these activities - science, regulation and marketing - are often closely connected to one another. However, this is not always the way in which they are being portrayed. For instance, academia and "the market" have regularly been described as a battlefield (e.g. Lien 1997; Long and Long 1992). Science, in this view, deals with universal truths while marketing is connected to personal preferences and the art of persuasion. Science is methodologically sound and marketing is not. While the actors starring at these fronts, academic researchers, and regulators at one end of the spectrum, and potential consumers at the other, demand a different logic, a different message, and different channels for communication, they also heavily depend on one another since the engineering of credibility among both - as we have tried to show in the credibility circle for Unilever - is closely intertwined.

While credibility engineering directed at consumers and credibility engineering directed at peers and regulators may often be staged as separate processes, within Unilever the boundary between them is quite permeable. This we say on the basis of our own study and analyses but people working in Unilever also say this rather directly. As one of the Unilever core team leaders argues: "If you want to take your project away from being solely about science, then you will have to look at a communication strategy. What do you want to publish, both in- and outside of science? What do you want to tell to whom?” (Interview V2, 20090316). This team leader champions an integrated process of credibility management in which consumers, regulators, and scientists, alongside many others, are addressed side by side whereby knowledge, issues, publics, and credibility among both are constructed in parallel.

An interesting illustration of the parallel strategy of connecting science, regulation, and marketing, is Unilever's "Strategy for Indirect Communication." This strategy was, 
for example, used in the preparation for developing and launching the margarine spread "Blue Band Idea" (Unilever 2007). The strategy provided an integrated approach to the question who should be convinced of what message or claim. As such, the strategy dealt with getting a certain message to a large variety of actors, ranging from scientists to consumers.

The primary consumer was, in the case of Blue Band Idea, the mother. The message to be communicated to her was to make her aware of the importance of education and learning and what a product like Blue Band Idea can add to this process ("awareness, credibility, and education"). The primary goal was articulated as follows: "To build credibility for nutritional benefit of [Blue Band Idea]." The strategy featured television commercials, mothers and their surroundings; as well scientists, policymakers, and many more who were actors. Unilever's strategy for indirect communication asked "Who influences a mother about healthy nutrition and mental development of her children?" and answered this question ${ }^{20}$ by presenting an elaborate network of influencers grouped as internal (private life contacts) and external (formal contacts). The network included, but was not limited to day care, schools, teachers, other children, books, advertisements, direct mail, general practitioners, books, psychologists, self-help groups, the internet, parent magazines, her own mother, peer mothers, dieticians, the government and governmental bodies, European health organization, national and European nutrition councils, neuro- and nutrition scientists, and many more. All of these actors presented channels for indirect communication of the product characteristics and claims, the credibility of those claims and the credibility of Unilever itself (see fig. 4).

The indirect communication strategy illustrates how the three processes that we have described so far - credibility engineering among scientists, among regulators, and among consumers, e.g. science and marketing - come together. These processes feed one another with capital and knowledge. Figure 5 presents a schematic impression of how they are connected.

The connection between the displayed parallel cycles is closely monitored by Unilever itself, but also by external experts. Within Unilever, experts operating at the intersection of science and the marketplace are known as key opinion formers (KOFs). A KOF is a public figure who operates in the boundary zone between science and the market place. KOFs include policymakers, scholars, and scientists. To academics, they are important sources for the societal orientation of science. To consumers, exchanges and discussions between Unilever and KOFs are accessible sources of information. In other words, KOFs critically compare parallel credibility engineering processes and report misfits. For instance, a highly visible KOF is the Dutch nutrition scientist

\footnotetext{
${ }^{20}$ As part of our research, we requested the file ourselves. Our non-disclosure agreement with Unilever acted as a backstage pass and we were given access. Due to its confidential character, we include no substantial segments here.
} 


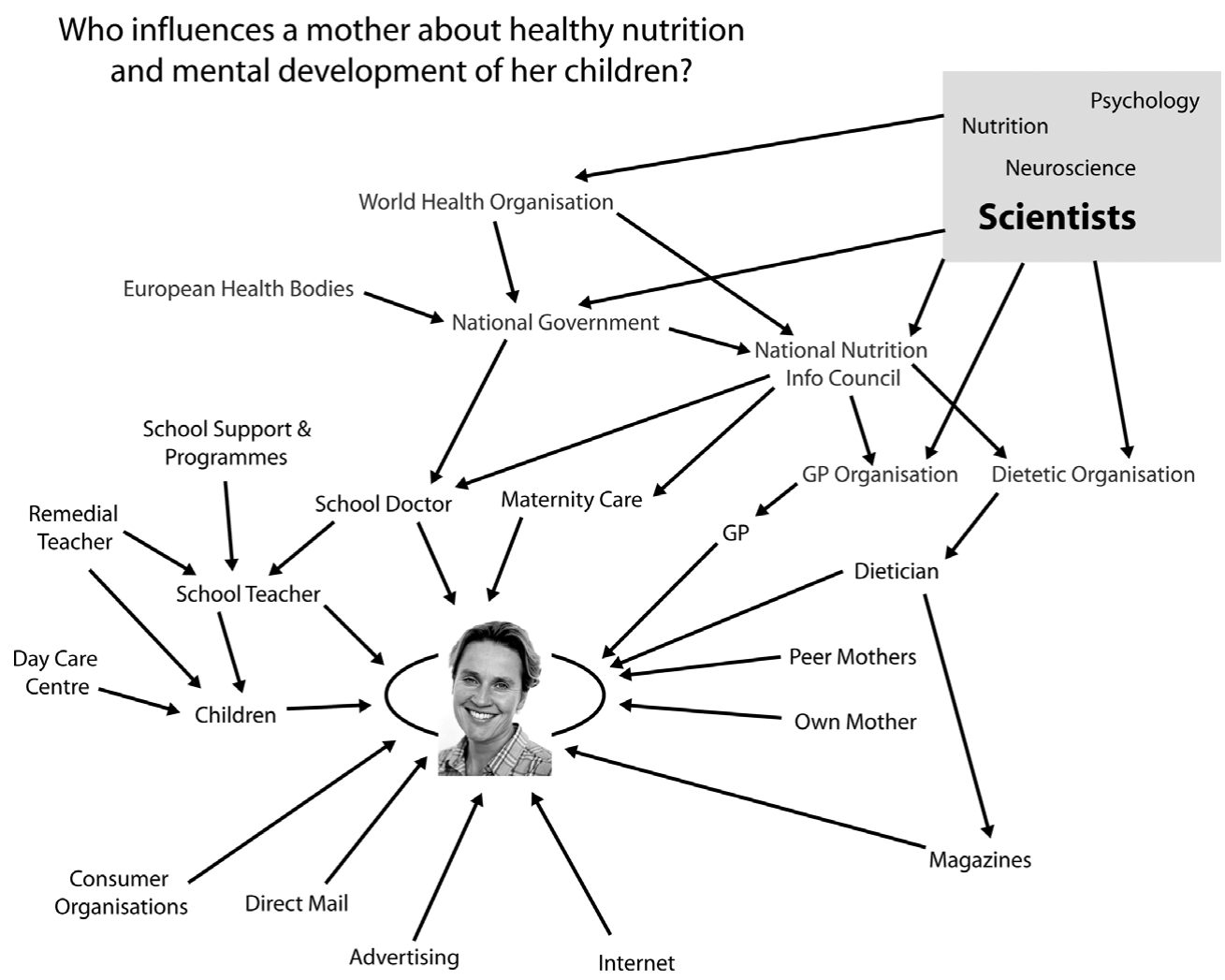

Fig. 4. Who influences a mother about healthy nutrition and mental development of their children? In the communication strategy, the central target in communication is reached via a variety of channels, directly via advertising and indirectly via science. Redrawn and simplified by BP from the Unilever Indirect Communication Strategy. Only a subset of the original nodes is shown. Due to portrait rights, the photograph has been replaced by that of APN.

Martijn Katan. ${ }^{21}$ Within Unilever, Katan is repeatedly identified as one of their KOFs (Observation V7, 20081110, Interview V2, 20081006, and Observation V1, 20080415). Amongst his peers he is held in the highest esteem while he also publishes for the lay public (see e.g. Katan 2008). Katan's popular science writings are closely followed and monitored by Unilever scientists. However, Unilever also communicates

\footnotetext{
${ }^{21}$ Amongst his peers he is held in the highest esteem and he has recently published a book for the lay public (Katan 2008). In this book he discusses the heterogeneity of nutritional expertise by discussing how science works: "at the front of science, there is chaos and contradiction" (ibid., 13) or "ask someone what healthy food is and 99 out of a 100 times you will get a firm answer. The one who doesn't know for sure, may be a nutritionist" (ibid., 11). In response to this heterogeneity, Katan claims that anything is good as long as you don't eat too much of it. His attempt to deal with heterogeneity fits within an idealist modern tradition in which the validity of a claim is considered to be the only relevant determinant of its credibility (Shapin 1995).
} 


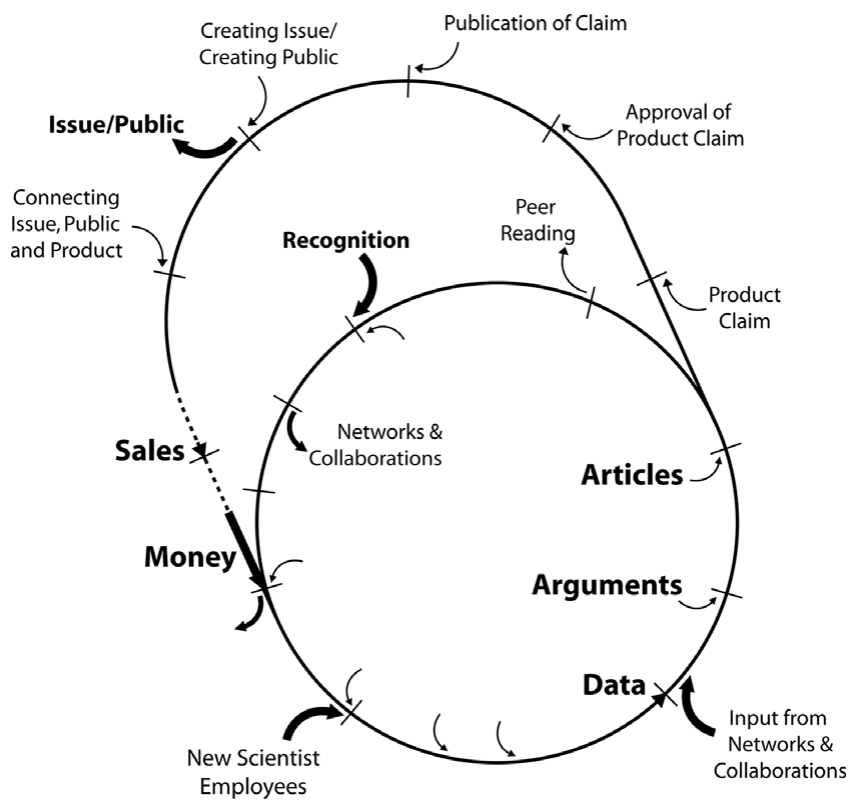

Fig. 5. The cycle of credibility expanded. Credibility engineering among peers, as well as among consumers are densely interconnected. The connections between the two are not articulated prominently. This double cycle is the integration or the merger of figures 2 and 3 , that between credibility engineering among nutrition science and among consumers.

intensively with KOFs like Katan. As one of the R\&D directors illustrates: "If Martijn Katan writes something in a newspaper which we do not fully agree with, we will just give him a ring" (Observation V1, 20080814). ${ }^{22}$

Credibility engineering by Unilever is a practice in which science, regulation, and marketing meet, in which scientists, regulators, and consumers are addressed side by side and in which scientific facts and persuasive strategies are mobilized alongside one another, and in which universal claims are made personal. ${ }^{23}$ The strict boundary which is often thought to exist between science and marketing is highly permeable and it is traversed regularly, although not so easily.

\footnotetext{
${ }^{22}$ However, disagreements between KOFs and Unilever may contribute to the heterogeneity which Shapin has argued may lead to a public "unconcern" - a disinterest which, especially in the case of matters concerning health, may be detrimental (Shapin 2007).

${ }^{23}$ Another way to think about this is in terms of the Mertonian norm of universalism. Scientists ideally gauge the credibility of a scientific claim not based on who is making it (particularistic criteria), but on the merit of the empirical or theoretical claim alone (universal criteria). Unilever does this through scientific accreditation processes (universal), but gathers further credibility with a different (non-science) approach which is very particularistic. In essence, linking the universal and the particularistic mechanisms of producing credibility into a single, holistic marketing campaign is more powerful than either alone.
} 


\section{Discussion}

In the previous paragraphs we have described the process of "credibility engineering" in the corporation Unilever. As we have shown, this process differs in a number of respects from credibility engineering in science. In science, scientific peers are the main source from which to gain credibility and it is they who attribute credits to one's ideas and knowledge. To Unilever, there are no less than three sources from which to gain credibility and together these contribute to the credibility of (new) products: scientific peers, regulators, and consumers.

Our focus on Unilever has enriched our understanding of what knowledge production and credibility engineering mean in this particular private industry. But what does this study tell us about credibility engineering in private industry in general? To what extent is the credibility cycle that we produced for Unilever able to represent and explain credibility engineering in other industries? How does our argument apply to other industries and what does it imply for other practices?

As we indicated in the introduction, there are only few scholars who address knowledge production in corporate science. As a result of this, there are few resources to help answer the question if and how our extended credibility cycle reflects overall credibility engineering in private industry. A prominent exception is Sergio Sismondo, who has, among other things, studied scientific knowledge production in the pharmaceutical industry. From the work of Sismondo we learn that credibility engineering in the pharmaceutical industry does not necessarily compare to credibility engineering within Unilever or the food industry.

In contrast to what we saw within Unilever, pharmaceutical companies today outsource a lot of their scientific work, essentially buying scientific authority and credibility through ghost authorship strategies (Sismondo 2009a). Most of this work is handled by contract research organizations that are made up of planners and planning teams: "the data that is being produced is typically analyzed by pharmaceutical companies statisticians, papers are written by medical writers, and the whole process is guided and shepherded through to publication by planners and planning teams" (ibid., 172). Papers are produced under the name of one or more medical specialists, preferably, key opinion leaders (KOLs): "The KOLs are valuable to the credibility of the manuscript and therefore essential to the whole project of publication planning. ... Planners can work to create authors out of KOLs" (ibid., 187). The work of the employees of the contract research organization, such as the statisticians and medical writers, however, rarely gets mentioned in journal publications and other output. For this reason, Sismondo argues, "we might see publication planning as the 'ghost management' of medical research" (ibid.).

Sismondo describes two separate worlds responsible for academic publishing in the pharmaceutical industry: professional planners and medical or clinical specialists. He shows that professional planners do a lot to maintain their credibility as honest professionals. Planners are well aware of the sensitivities that guide their work. As one 
of them says to Sismondo: "We really do like to stress that the publication planning company is not an advertising agency, is not a PR agency, even though it might look like one" (ibid., 179). Planners understand that their work has marketing value and that it is exactly for that value that their work is supported. However, they see a clear distinction between their own work and that of marketing people. Marketing, according to planners, "would consistently ride roughshod over scientific standards, and in particular be relatively unconcerned with what the scientific data can support" (ibid., 181) rather than apply to good publication practice. "A publication plan is a basis for dissemination for scientific and clinical data and is "not a marketing communications plan"” (ibid.).

If we compare how the pharmaceutical sector aims to generate credibility for its (scientific) results and its products with what we have learned from Unilever, we encounter some substantial differences. First, both deal with different consumers. First, in both cases we see a different division of labor and different dependencies between the "specialties" of science and of marketing. Second, making use of external parties such as CROs and publication planners - to organize part of the credibility process, makes this process less transparent. ${ }^{24}$

In both examples - food and pharma - we encounter different customers. In the pharmaceutical industry, credibility engineering is directed to one audience: medical professionals. They are the gatekeeper between the pharmaceutical industry and patients or citizens and thus the audience of both marketers and scientists. Within the food industry products are being marketed directly to (potential) consumers and citizens. For medical professionals, peer-review is an important indicator and thus will be used in marketing strategies. Peer reviewed literature, however, is not a way to reach consumers and citizens and cannot directly act as a marketing tool in Unilever's marketing strategy. The links between marketing and R\&D as described by Sismondo are exclusive to the pharmaceutical industry (Sismondo 2007, 2009a, 2010), whereas the interaction between marketing and R\&D we observed in Unilever (and Lehenkari observed with Raiso) probably is more specific for consumer-industries. Thus, both sectors differ significantly in their credibility strategies and what counts as a product that is trusted (i.e. having the status of being credible) and sold.

The dependencies between science and marketing differ. In both cases, scientific publications that support certain ideas or knowledge are needed to gain credit for a particular product. Nevertheless, the food industry and the pharmaceutical industry differ in terms of how the publication process is organized. In pharmacy, the production of scientific papers is being orchestrated by contract research organizations. Credibility engineering among scientists, so it seems, is diverted, outsourced, or disconnected from marketing activities. As the quotes from the scientific planners illustrate, these

\footnotetext{
${ }^{24}$ No doubt, if we were to do a more extensive comparison between the two industries, we would probably come up with even more differences. For example, the way in which the regulatory regime is organized also asks for further exploration.
} 
planners see a sharp distinction between themselves and the marketing people. In the eyes of the planners, marketing people are prepared to sell anything. In the pharmaceutical industry, there is little connection between the strategies of the external planner and the marketing people. In the case of Unilever, however, science and marketing are very much part of the same process whereby both people and strategy are intertwined and connected. ${ }^{25}$ An exemplar of this we find in Unilever's Strategy for Indirect Communication (paragraph 7). This strategy brings together different audiences (consumers, regulators, KOFs, scientists, and policymakers) and sources that may acclaim their products.

Making use of external parties to organize part of the credibility process, makes this process less transparent. Both pharmaceutical industry and food companies produce scientific articles claiming credibility for their novel products and the science behind these new products. However, in pharmaceutical companies this work is done by ghost-writers and hidden workers. In Unilever this is done by the company's own scientists. The latter process therefore seems more transparent than it is in pharma. The pharmaceutical sector hosts a hidden workforce that is neither mentioned nor credited for the work they do. While professional planners do the work, KOLs get the credit. Here, the KOLs are not used as sources of expertise, but rather as sources of authority, sought after to endorse rather than to contribute or critique corporate science. $^{26}$

Of course, there are also similarities between the pharmaceutical companies and Unilever. Elements of the novel model of science Sismondo described in his paper overlap with observations we have made during our study of Unilever R\&D: the high commercial stakes, the size of the workforce, and the much broader networks of professionals actively involved in knowledge production. Also, the motives for producing scientific publications are comparable. When we look at the extended credibility cycle, it is questionable to what extent an analyses of the pharmaceutical industry would lead to a similar cycle.

\footnotetext{
${ }^{25}$ It is, however, important to consider that in two countries, namely New Zealand and the United States, direct to consumer (DTC) marketing of pharmaceuticals is allowed. As a result, in those two countries, credibility engineering may resemble the dynamic described in this paper a lot more than the one described by Sismondo. For instance, Busfield 2006 discusses the sociological strategies for "fact-making" for DTC marketing through clinical trial data and Conrad 2005 positions DTC advertising as part of the medicalization engine that is the pharmaceutical industry.

${ }^{26}$ Studying corporations and their ways of knowledge production invites critical normative positions. For example, after Sismondo described how the medical writing industry intertwined marketing and research into new drugs (Sismondo 2009a), he was immediately criticized by his own peers for not condemning the pharmaceutical sector for this and for not accusing them of improper science (McHenry 2009). He responds by demonstrating that the practice described in his paper exposes choices and decisions made, but that it need not be considered bad or faulty science (Sismondo 2009b). This does not exclude Sismondo from harshly criticizing these choices elsewhere (Sismondo and Doucet 2010).
} 
What we have shown here is that credibility engineering is an integrated endeavor and that it consists of a single, expanded credibility cycle ${ }^{27}$ and that indeed "research does not have an intrinsic value that automatically confers credibility" (Lehenkari 2003, 520). In fact, amongst the many and difficult translations that take place during the engineering of credibility, only a modest role is reserved for science. In the words of Knorr Cetina, both we and Lehenkari have been studying transepistemic arenas in which credibility will have to be tied into local relevance, which can and will be very different from the ones in $\mathrm{R} \& \mathrm{D}$ and which require continuous maintenance (Knorr Cetina 1982). ${ }^{28}$

To what extent the local relevance of different private industries compare, is a question for future research. Different industries may mobilize different sets of strategies, based upon whether consumers and peers overlap (as they do in pharma), or the degree of heterogeneity present in the fields they are active in. Especially the discrepancies between Sismondo's and our analysis show that credibility engineering is a worthwhile starting point for a series of social studies of corporate science (Penders et al. 2009).

\section{Conclusion}

In this paper we have compared the process of knowledge production in public science and private industry. In particular, we have focused on the question how knowledge becomes "credible knowledge," to whom this "credibility" matters or applies, and with what effect.

In science, as first shown by Latour and Woolgar, credibility is linked to scientific authorship and the recognition of one's work by academic peers. What is "credible" knowledge is determined by academic peers who show their faith in the credibility of one's knowledge and ideas by citing from one's articles and books. Credit is granted for knowledge and claims that are new and have not been granted credit before. Through the distribution of credibility via peers, scientists gain further funding and opportunities for future research.

In the case of Unilever, not only scientific credibility but also recognition from regulators and consumers turned out to be important to the process of knowledge production. Regulators, like peers, give credit to particular claims in light of the scientific evidence available at a particular moment in time. Here, credit is defined not by the fact that knowledge is new and not previously credited to other scientists or groups but by the fact that this knowledge aligns with the scientific consensus. It has to be, in other words, based on credible knowledge. Consumers, according to the

\footnotetext{
${ }^{27}$ Here, we significantly differ in our analysis from Lehenkari (2000, 2003), who argues that three temporally and geographically separated cycles can account for the emergence and maintenance of credibility.

${ }^{28}$ Like everything that is engineered, without active and careful maintenance, credibility may become vulnerable.
} 
marketers of Unilever (but also Shapin), are neither primarily interested in the evidence base of (food) claims nor in the novelty of such claims. Much more, they are interested how a particular claim fits their personal situation or life-style. How, in other words, it relates to them individually. What makes a claim "credible" is if it links with an issue that consumers consider to be their issue.

To accommodate the above, we have extended the credibility cycle with an additional "loop." The basic cycle that Latour and Woolgar describe and that represents the production of new knowledge and getting credit for this knowledge, in essence, in Unilever is hardly different from processes in academic science. In addition, there is an additional loop that represents the acquiring of credibility from regulators, to match claims with accredited knowledge and to represent the involvement of customers in the credibility process of a product or claim.

Most of all, what we have shown to be specific to Unilever, compared to Sismondo's pharmaceutical industry, is that obtaining credibility from scientific peers, regulators, and consumers is one and the same process. Unilever's communication strategy and also the way the company organizes its work processes includes the development, marketing, and sales of new knowledge and products. As a result, the credibility of Unilever's products, in general, are determined by the weakest link in the credibility circle. Sometimes that is science and sometimes it isn't. Credibility engineering, in other words, is "big business."

\section{Acknowledgments}

This study was conducted under auspices of the Center for Society and Genomics, a Center of Excellence funded by the Netherlands Genomics Initiative. We thank all the people at Unilever R\&D, at Vlaardingen and elsewhere, who participated in our research. While Unilever provided full cooperation, it did not financially contribute to the research or influence its outcome. We thank John Parker, Maud Radstake, David Schleifer, Jeanette Simmonds, and two anonymous reviewers for valuable comments that helped improve this text.

\section{References}

Atkins, Robert C. 1994. Dr. Atkins' New Diet Revolution. New York: M. Evans \& Company.

Bal, Roland. 2005. "How to Kill with a Ball-point: Credibility in Dutch Forensic Science." Science, Technology and Human Values 30:52-75.

Banga, Vanga. 2006. "Vitality in Action. Unilever's Consumer Insights." Barcelona: Unilever.

Barrow, Craig. S. and James W. Conrad. 2006. "Assessing the Reliability and Credibility of Industry Science and Scientists.” Environmental Health Perspectives 114:153-155.

Busfield, Joan. 2006. "Pills, Power, People: Sociological Understandings of the Pharmaceutical Industry." Sociology 40:297-314.

Cambrosio, Alberto, Peter Keating, Thomas Schlich, and George Weisz. 2006. "Regulatory Objectivity and the Generation and Management of Evidence in Medicine.” Social Science and Medicine 63:189-199. 
Collins, Randall. 1975. Conflict Sociology: Toward an Explanatory Science. New York: Academic Press.

Conrad, Peter. 2005. "The Shifting Engines of Medicalization." Journal of Health and Social Behavior 46:3-14.

EFSA. 2008. "Scientific opinion of the Panel on Dietetic Products Nutrition and Allergies on a request from Unilever PLC/NV on Plant sterols and lower/reduced blood cholesterol, reduced the risk of (coronary) heart disease." EFSA Journal 781:1-12.

Fieldhouse, David K. 1978. Unilever Overseas. The Anatomy of a Multinational. Stanford CA: Hoover Institution Press.

Gylling, Helena, Maarit Hallikainen, Radhakrishnan A. Rajaratnam, Piia Simonen, Jussi Pihlajamäki, Markku Laakso, and Tatu A. Miettinen. 2009. "The Metabolism of Plant Sterols Is Disturbed in Postmenopausal Women with Coronary Artery Disease." Metabolism: Clinical and Experimental 58:401407.

Hessels, Laurens K., Harro van Lente, and Ruud Smits. 2009. "In Search of Relevance: The Changing Contract between Science and Society." Science and Public Policy 36:387-401.

Jones, Geoffrey. 2005. Renewing Unilever. Transformation and Tradition. New York: Oxford University Press. Katan, Martijn B. 2008. Wat is nu gezond? Fabels en feiten over voeding. Amsterdam: Bert Bakker.

Katan, Martijn B., S. M. Grundy, P. Jones, M. Law, T. Miettinen, and R. Paoletti. 2003. "Efficacy and Safety of Plant Stanols and Sterols in the Management of Blood Cholestrol Levels." Mayo Clinic Proceedings 78:965-978.

Kinchy, Abby J. and Daniel Kleinman. 2003. "Organizing Credibility: Discursive and Organizational Orthodoxy on the Borders of Ecology and Politics." Social Studies of Science 33:869896.

Knorr Cetina, Karin D. 1982. "Scientific Communities or Transepistemic Arenas of Research? A Critique of Quasi-Economic Models of Science." Social Studies of Science 12:101-130.

Lang, Tim, and Michael Haesman. 2004. Food Wars. The Global Battle for Mouths, Minds and Markets. London: Earthscan.

Latour, Bruno and Steve Woolgar. [1979] 1986. Laboratory Life: The Construction of Scientific Facts. Princeton: Princeton University Press.

Lehenkari, Janne. 2000. "Studying Innovation Trajectories and Networks: The Case of Benecol Margarine." Science Studies 13(1):50-67.

Lehenkari, Janne. 2003. "On the Borderline of Food and Drug: Constructing Credibility and Markets for a Functional Food Product." Science as Culture 12(4):499-525.

van Lente, Harro, and Arie Rip. 1998. "The Rise of Membrane Technology: From Rhetoric to Social Reality." Social Studies of Science 28:221-254.

van Lente, Harro and Jon I. van Til. 2008. "Articulation of Sustainability in the Emerging Field of Nanocoatings." Journal of Cleaner Production 16:967-976.

Lien, Marianne E. 1993. "From Deprived to Frustrated. Consumer Segmentation in Food and Nutrition." In Regulating Markets, Regulating People, edited by U. Kjærnes, L. Holm, M. Ekström, E. L. Fürst, and R. Prättälä, 153-171. Oslo: Novus Forlag.

Lien, Marianne E. 1997. Marketing and Modernity. Oxford/New York: Berg.

Long, Norman, and Ann Long. 1992. Battlefields of Knowledge: The Interlocking of Theory and Practice in Social Research and Development. London: Routledge.

Lynch, Michael. 2002. "'Science above all Else'. The Inversion of Credibility between Forensic DNA Profiling and Fingerprint Evidence." In Expertise in Regulation and Law, edited by Gary Edmond, 121-135. Aldershot: Ashgate.

Marres, Noortje. 2007. "The Issues Deserve More Credit: Pragmatist Contributions to the Study of Public Involvement in Controversy." Social Studies of Science 37:759-780.

McHenry, Leemon. 2009. "Ghosts in the Machine: Comment on Sismondo." Social Studies of Science 39:943-947.

Merton, Robert K. 1968. "The Matthew Effect in Science. The Reward and Communication Systems of Science Are Considered.” Science 159:56-63. 
Nestle, Marion. 2002. Food Politics: How the Food Industry Influences Nutrition and Health. Berkeley CA: University of California Press.

Nowotny, Helga, Peter Scott, and Michael Gibbons. 2001. Re-thinking Science. Knowledge and the Public in an Age of Uncertainty. London: Polity.

Packer, Kathryn and Andrew Webster. 1996. "Patenting Culture in Science. Reinventing the Scientific Wheel of Credibility." Science, Technology and Human Values 21:427-453.

Penders, Bart, John M. A. Verbakel, and Annemiek P. Nelis. 2009. "The Social Study of Corporate Science: A Research Manifesto." Bulletin of Science, Technology and Society 29:439-446.

Perry, Eevelyn M., Joe M. Mata, and Thomas M. Gieryn. 2007. "Science and the Discursive Politics of Policy: Examining Credibility and Policy Framing." Annual Meeting of the American Sociological Association. New York.

Rip, Arie. 1994. "The Republic of Science in the 1990s." Higher Education 28:3-23.

Ronteltap, Amber. 2008. Public Acceptance of Nutrigenomics-based Personalised Nutrition. Exploring the Future with Experts and Consumers. Wageningen: Wageningen University and Research Center.

Shapin, Steven. 1995. "Cordelia's Love: Credibility and the Social Studies of Science." Perspectives on Science 3:255-275.

Shapin, Steven. 2007. "Expertise, Common Sense and the Atkins Diet." In Public Science in Liberal Democracy, edited by Jene M. Porter, and Peter W. B. Phillips, eds., 174-193. Toronto: University of Toronto Press.

Shapin, Steven. 2008. The Scientific Life. A Moral History of a Late Modern Vocation. Chicago/London: University of Chicago Press.

Simon, Michele. 2006. Appetite for Profit. How the Food Industry Undermines Our Health and How to Fight Back. New York: Nation Books.

Sismondo, Sergio. 2007. "Ghost Management: How Much of the Medical Literature Is Shaped Behind the Scenes by the Pharmaceutical Industry?” PLoS Medicine 4:e286.

Sismondo, Sergio. 2009a. "Ghosts in the Machine: Publication Planning in the Medical Sciences." Social Studies of Science 39:171-198.

Sismondo, Sergio. 2009b. "Ghosts in the Machine: Reply to McHenry." Social Studies of Science 39:949952.

Sismondo, Sergio. 2010. "Linking Research and Marketing, a Pharmaceutical Innovation." In Perspectives on 20th Century Pharmacenticals, edited by Viviane Quirke and Judy Slinn, 241-256. New York: Peter Lang.

Sismondo, Sergio and Mark Doucet. 2010. "Publication Ethics and the Ghost Management of Medical Publication." Bioethics 24:273-283.

Smith, Adrian, Andy Stirling, and Frans Berkhout. 2005. "The Governance of Sustainable Socio-Technical Transitions." Research Policy 34:1491-1510.

Truswell, A. Stewart. 2001. "Levels and Kinds of Evidence for Public-Health Nutrition." Lancet 357:10611062.

Unilever. 2007. "Indirect Communication Strategy." 24. Rotterdam/Vlaardingen: Unilever.

Unilever. 2009a. "Successful Campaign for Becel and Care for Women. Women of 50+ More Aware of Cholesterol Risks." Unilever Vitality News 2:1.

Unilever. 2009b. Creating a Better Future Every Day. Annual Report and Accounts 2009. Rotterdam/London: Unilever NV/PLC.

Weingärtner, Oliver, Dieter Lütjohann, Shengbo Ji, Nicole Weisshoff, Franka List, Thomas Sudhop, Klaus von Bergmann, Karen Gertz, Jochem König, Hans-Joachim Schäfers, Matthias Endres, Michael Böhm, and Ulrich Laufs. 2008. "Vascular Effects of Diet Supplementation With Plant Sterols." Journal of the American College of Cardiology 51:1553-1561.

Wilson, Charles. [1954/1968] 1970. The History of Unilever. A Study in Economic Growth and Social Change. 3 Vols. London: Cassell.

Wubs, Ben. 2008. International Business and National War Interests. Unilever between Reich and Empire, 193945. London/New York: Routledge. 